\title{
Minor Volatile Compounds in Traditional Homemade Fruit Brandies from Transylvania-Romania, as Determined by GC-MS Analysis
}

\author{
Teodora Emilia COLDEA ${ }^{1}$, Carmen SOCACIU ${ }^{1 *}$, \\ Zaharie MOLDOVAN ${ }^{2}$, Elena MUDURA ${ }^{1}$ \\ ${ }^{1}$ University of Agricultural Sciences and Veterinary Medicine Cluj-Napoca, Faculty of Food Science and Technology, 400372 Calea Manastur 3-5, \\ Cluj-Napoca, Romania; carmen.socaciu@usamvcluj.ro (*orresponding author) \\ ${ }^{2}$ National Institute of Research and Development for Isotopic and Molecular Technology, INCDTIM, 400293 Donath Street, Cluj-Napoca, Romania
}

\begin{abstract}
In order to investigate the minor volatile compounds of traditional homemade fruit brandies from Romania (Transylvania region), as a result of their assortment and provenience, a number of 26 samples (18 plum brandies samples from 3 different counties, 4 samples of apple brandy and 4 samples of pear brandy) were analyzed using liquid-liquid extraction and gaschromatography coupled with mass-spectrometry (GC-MS) technique. The GC-MS chromatograms of the hexane extracts led to the identification of 34 compounds ( 9 terpenes, 14 fatty acids esters, 3 free fatty acids, 4 carboxylic acid esters, 1 hydrocarbon, 1 aldehyde and 1 acetal). The most abundant compounds were the fatty acid esters. Chemometric analysis (Principal Component Analysis-PCA) was applied to discriminate the differences between the volatiles' fingerprint. Considering the plum brandy samples, significant differences have been observed according to their provenience region. Based on relative abundance of determined compounds important differences among samples from different counties can be seen.. Ethyl hexadecanoate was the main factor for this discrimination. When compared the three types of fruit brandies, significant differences were noticed for their content in ethyl esters of hexanoic, benzoic and hexadecanoic acids. For some plum brandies, according to their fingerprint, possible adulteration with apple brandy can be noted, based on their similar volatiles' pattern. The pear brandy was strongly delimitated by the other two types of brandies. The PCA data showed a good discrimination according to the region of provenience of the plum brandies in parallel with the composition specificity of the three analyzed fruit brandies.
\end{abstract}

Keywords: fruit brandies, GC-MS, minor volatile compounds, PCA, Romania

\section{Introduction}

Some Central and East European countries are famous for their tradition in fruit brandies production, such as Slovakia (bošácka slivovica), Czech Republic (slivovice), Bulgaria (slivova rakya), Hungary (pálinka), Poland (śliwowica tacka), and at a lower extent Germany (Zwetschgenwasser), France (Kirsch d'Alsace), Luxemburg (eau-de-vie de prunelles de marque nationale luxembourgeoise) and Austria (Wachauer Marillenbrand) (Regulation (EC) No. 110/2008; Satora and Tuszynski, 2008).

The secrets of natural spirits or brandy manufacturing have been passed from generation to generation through practice and by word of mouth, kept very strictly to be shared with others in writing.

Romania has a long tradition of manufacturing natural fruit brandies. In many regions the distillate becomes a real badge for them. Although the technologies of traditional drinks are not much different for each production area, the personality and the characteristics of products are due to the raw materials and the state of the mash distillation process.
According to European regulation (Regulation (EC) No. 110/2008) and Romanian legislation (Order No. $368 / 2008$ ), there are 14 different assortments of fruit spirits as Protected Geographical Indication products.

Truica is a traditional and autochthonous Romanian spirit drink produced exclusively by alcoholic fermentation and distillation of plums (different varieties), whole or crushed, or juice made from plums, in the presence or absence of stones. In geographical areas Maramuress and Oas, tuica may be called horincă or turț. The minimum alcoholic strength is different for each traditional area and depending on the manufacturing process, but not less than $24 \%$ vol. alcohol.

Palinca is also a traditional spirit drink produced by fermentation and distillation of fleshy fruits, a mixture of fruits or fruits marc, the fruit juice, in the presence or absence of stones. The north-west region of Transylvania is called Country of pălinca and includes counties Maramures, Satu Mare, Sălaj, Bistrita-Năsăud, Bihor and Cluj (Pomohaci et al., 2009). The minimum alcoholic strength for pălinca is $40 \%$ vol. alcohol. 
531

The traditional manufacturing process involves harvesting of fruits, preparing the fruits for fermentation, fermentation of fruits, and distillation of mash. The crude spirits are than maturated and aged to increase the sensorial properties.

Healthy fully mature or overmature fruits of plums, pears or apples, are harvested by shaking early in the morning or in the evening when the temperature of the fruits is approximately equal with the air temperature. In most cases, because of the traditional character of these products, the fruits are carried to farmer's installation into small wooden baskets of 5-20 L capacity. For traditional spirits manufacturing the local producers avoid washing the fruits. The fruits were immediately milled (without removing the stones, but avoiding their crashing, in the case of plums) and then transferred for spontaneous fermentation in wooden, plastic and less stainless steel fermenting vessels. The most used are tight wooden vessels less than 1 meter width and more 2 meters height (Pomohaci et al., 2009). The vessels are filled to total capacity and sits under an awning. The fermentation is done by spontaneous yeasts from raw fruits. The fermentation time is influenced by type and capacity of the vessels, by ambient temperature and by the manufacturing process. For Romanian climate, a medium temperature of $15-20^{\circ} \mathrm{C}$ is most popular in the harvest time and for this condition the fermentation process is ready in less than 15 days. The end of fermentation time is done by empirical method by taste and by visual assessment of carbon dioxide release. The fermented marc is immediately distillated to prevent alcohol loss.

The distillation is done in copper still with open fire at an alcoholic strength that not exceeding $86 \%$ vol. for tuica and $70 \%$ vol. alcohol for pălinca. The distillate must keep fruit flavor; redistillation at the same alcoholic strength is authorized by Romanian legislation (Beceanu and Niculaua, 2009).

The copper alembic is a simple installation for distillation (Fig. 1). The main parts consist of boiler for marc heating, the steam dome where alcoholics add up and the condenser for distillate collection. The heating with open fire is made with caution to avoid the sudden increase in temperature and prevent the marc burning.

The management of distillation process is done by master man, which uses traditional methods for properly separation of fractions. The heads drawn off first and are collected separately. The tuica is the middle fraction. The tails are cuts off when the spirits is burning with yellow flame if a small quantity of liquid is poured on the top of copper still.

The fresh fruits spirits are maturated in wooden barrels and optionally aging in bottle. Maturation is responsible for the non-volatile components of spirits. The oak barrels are most popular, but also the mulberry, chestnut, willow or beech species are used. The maturation can be done also in glass vessels to keep the initially colorless and the flavor of raw materials fruits. The paper purpose is investigation for chemical and volatile composition of different fruit brandies processed from stone fruits and pomes fruits. The main technique applied for analyzing these beverages is gas chromatography coupled with mass spectrometry (GC-
MS). Some papers reported data on analyzed alcoholic beverages in the last decade, as old plum brandies (Tešević $e t$ al., 2005), cornelian cherry (Tešević et al., 2009), fruit brandies produced in Slovack Republic (Janáčová et al., 2008; Satora and Tuszynski, 2005, 2008), Turkish Raki (Anli et al., 2007), apple distillate (Versini et al., 2009) or grape marc distillate (Lukić et al., 2011).

The volatile components are responsible for the quality and safety of fruit brandies, depending on their composition, concentration and sensorial properties, essential for customer's acceptance. The qualities of raw materials, but also fermentation and distillation technology as well and brandy maturation are main factors responsible for the specific flavour of fruit brandies. The volatile compounds of alcoholic beverages were analyzed using different extraction methods such as distillation techniques, liquid-liquid extraction (Caldeira et al., 2004; Christopoulou-Gerogiannaki et al., 2007; Lukić et al., 2011; Tešević et al., 2005; Tešević et al., 2009), solid phase extraction (SPE) (Sohrabvandi et al., 2011), solid phase microextraction (SPME) (Plutowska et al., 2010), in-tube extraction (Laaks et al., 2014), headspace solid-phase microextraction (HS-SPME) (Butkhup et al., 2011; De León-Rodríguez et al., 2008; Rodrigues et al., 2008), supercritical fluid extraction (SFE) (Gracia et al., 2009) and stir bar sorptive extraction (SBSE) (Delgado et al., 2010).

Volatiles that give to an alcoholic beverage its specific flavour can be determined and used to classify these drinks by type, country and even the provenience region. The analysis taken on these types of beverages have significant importance in controlling and preventing fraud in this area. Most of the knowledge gained so far on aroma of fruit brandies has come from studies of gas-chromatography analysis, which is the mostly used technique (Anli et al., 2007; Cabaroglu and Yilmaztekin, 2011; Cardoso et al., 2004; Janáčová et al., 2008; Lukić et al., 2011; Plutowska et al., 2010; Satora and Tuszynski, 2008; Vera-Guzmán et al., 2010; Versini et al., 2009, 2012). Among major volatile compounds reported by other references in different types of alcoholic beverages were: acetaldehyde (Cabaroglu and Yilmaztekin, 2011; Cortés et al., 2011; Hernández-Gómez et al., 2008; Lukić et al., 2011; Sarvarova et al., 2011; Satora and Tuszynski, 2010; Soufleros et al., 2005; Tešević et al., 2009; Winterová et al., 2008), ethyl acetate, methanol (Cabaroglu and Yilmaztekin, 2011; Cortés et al., 2011; De León-Rodríguez et al., 2008; Hernández-Gómez et al., 2008; Lukić et al., 2011; Sarvarova et al., 2011; Satora and Tuszynski, 2010; Soufleros et al., 2005; Tešević et al., 2009; Versini et al., 2009; Winterová et al., 2008), furan-2carbaldehyde (Cortés et al., 2011; De León-Rodríguez et al., 2008; Janáčová et al., 2008; Lukić et al., 2011; Sarvarova et al., 2011; Tešević et al., 2009; Versini et al., 2009) and higher alcohols (Cabaroglu and Yilmaztekin, 2011; Cortés et al., 2011; De León-Rodríguez et al., 2008; Gracia et al., 2009; Hernández-Gómez et al., 2008; Lukić et al., 2011; Sarvarova et al., 2011; Soufleros et al., 2005; Tešević et al., 2009; Versini et al., 2009; Winterová et al., 2008). Considering the minor volatiles, were identified terpenes 
such as limonene (Tešević et al., 2005; Tešević et al., 2009), eugenol (Janáčová et al., 2008; Tešević et al., 2005; Tešević et al., 2009; Versini et al., 1995; Versini et al., 2009; Winterová et al., 2008), alfa-farnesene (Versini et al., 2009) or caryophyllene (Tešević et al., 2009). Long chain free fatty acids were also reported in fruit brandies (ChristopoulouGerogiannaki et al., 2007; Hernández-Gómez et al., 2005; Janáčová et al., 2008; Tešević et al., 2005; Tešević et al., 2009) and esters (Christopoulou-Gerogiannaki et al., 2007; Diban et al., 2009; Hernández-Gómez et al., 2005; Janáčová et al., 2008; López-Vázquez et al., 2010; Tešević et al., 2009; Versini et al., 2009; Winterová et al., 2008), together with carboxylic acid esters (López-Vázquez et al., 2010; Tešević et al., 2009; Versini et al., 1995; Versini et al., 2009).

The aim of this study was to extend the volatile compounds screening of traditional fruit brandies in order to discriminate them by raw materials and origin. To achieve this goal, different plum, apple and pear brandies were analyzed by applying the gas chromatography coupled with mass spectrometry (GC-MS). The principal component analysis (PCA) was further employed to identify the specific compounds depending on the type of brandy and the provenience region of fruit brandies. This is the first study regarding the minor volatile compounds' profile of traditional homemade fruit brandies originated from Transylvania, Romania.

\section{Materials and methods}

\section{Sampling}

A total number of 26 samples of fruit brandies (plum, apple and pear) made in different counties of Transylvania, the central part of Romania such as: Maramureş (MM), Cluj (CJ), Bistrita-Năsăud (BN), Alba (AB), Bihor (BH) as matured brandies samples were colleted directly from producers (Tab. 1). All the analyzed brandies were produced by traditional method. Fruit brandy samples were analyzed after two months of maturation.

\section{Liquid-liquid extraction}

All samples were extract-free and needed no previous treatment. For the extraction of volatile compounds from all brandies n-hexane (Riedel-de Haën, Hanover, Germany) with 99\% purity was used, friendly (non-aggressive) compound relative to chlorinated solvents. A volume of $250 \mathrm{~mL}$ of each sample was twice extracted with $5 \mathrm{~mL}$ n-hexane using a separation funnel. The samples were shaken for 1 hour than were transferred to vials and the excess of solvent was concentrated to $3 \mathrm{~mL}$ under nitrogen (Moldovan, 2006; Tešević et al., 2005). The resulted extract was transferred in sealed vials and stored at $0-8{ }^{\circ} \mathrm{C}$ until the chromatographic analyses were carried out. The extraction and run injection were performed in duplicate for each sample.

\section{Gas chromatography}

Volatile compounds were analyzed by GC-MS using a gas chromatograph TRACE GC ultra model (Thermo Fisher Scientific Inc., Waltham, MA, USA) coupled with Polaris Q mass spectrometer. One microliter of sample was injected. For compounds separation an Agilent HP-5ms fused-silica capillary column (Agilent Technologies Inc., Wilmington, DE, USA)
(30 m x $0.25 \mathrm{~mm} \times 0.25 \mu \mathrm{m}$ ) was used. Stationary phase was 5\% phenyl, 95\% dimethylpolysiloxane. The gas carrier was Helium $(1.5 \mathrm{~mL} / \mathrm{min})$. The injector temperature was $250^{\circ} \mathrm{C}$. The oven temperature was held at $60^{\circ} \mathrm{C}$ for $1 \mathrm{~min}$ than raised to $240{ }^{\circ} \mathrm{C}$ at the rate of $6^{\circ} \mathrm{C} / \mathrm{min}$ and held at $240^{\circ} \mathrm{C}$ for $5 \mathrm{~min}$ than raised to $303^{\circ} \mathrm{C}$ at the rate of $7^{\circ} \mathrm{C} / \mathrm{min}$ (by keeping this temperature for $1 \mathrm{~min}$ ). The compounds were identified based on their mass spectrum (in full scan mode at $70 \mathrm{eV}$ ) by comparison with mass spectra libraries (National Institute of Standards and Technology).

Each minor volatile compound was quantified based on peak area of the base ion. The relative content of the volatiles was calculated according to the formula: $A=\left(\mathrm{A}_{\mathrm{i}} / \Sigma \mathrm{A}_{\mathrm{i}}\right) \times 100$, where A represents the relative content (expressed in percentage) and $\mathrm{A}_{i}$ is the area calculated for each minor volatile compound identified by GC-MS analysis. As qualitative fingerprint applied, no internal standard was needed considering the screening done.

\section{Data validation}

The detector linearity was good having the correlation coefficient on individual compounds in the range 0.9811 0.9925. The Relative Standard Deviation (RSD) was in the range $1.5-6.9 \%$ and repeatability between $4.25-19.66 \%$. Limit of quantification (LOQ) obtained was in the range $6-98 \mu \mathrm{g} / \mathrm{L}$.

The purpose of the paper is a comparison of the products based on relative abundance of the main aroma compound and therefore the resulted conclusions are very suitable for a comparative description of the natural compounds - every selected compound from Tab. 3 was determined in each sample.

\section{Principal Component Analysis}

For the chemometric interpretation of data, Principal Component Analysis was made using the Unscrambler v.10.1 Software (Camo Software AS, Oslo, Norway). PCA is a useful tool for screening; extracting and compressing data, by a mathematical procedure to transform a set of possibly correlated response variables into a set of values of uncorrelated variables called principal components. In this case, the discrimination between different samples was done, based on main volatile components.

\section{Results and discussions}

\section{GC-MS Analysis of plum brandies}

By GC-MS analysis there were identified, in plum brandy samples, originating from $\mathrm{CJ}, \mathrm{MM}$ and $\mathrm{BN}$ regions, around 34 volatiles, as presented in Tab. 2. Their successive is dependent on the retention time. The mean values of the percentage (relative content) of each component are also presented.

Terpenes, esters of fatty acids or phenolic acids, free fatty acids and aldehydes were present in different proportions. Out of these molecules, the esters were the most abundant, reaching to around $80 \%$ in MM plum brandies (Fig. 2).

However, the major peaks identified correspond to ethyl esters of fatty acids (69.53-73.60\%) starting with esters of octanoic acid to ethyl ester of octadecanoic acid (Tab. 2).

From all minor volatiles, significant differences between plum brandies from $\mathrm{CJ}, \mathrm{BN}$ and MM Counties were obtained. The compounds which discriminate very well the three regions in the case of plum brandies are fatty acids esters starting with 
Tab. 1. Fruit brandies samples (plum - P, apple - M, pear - PE) with their provenience region

\begin{tabular}{|c|c|c|c|c|c|c|c|c|c|}
\hline Code & Region & Code & Region & Code & Region & Code & Region & Code & Region \\
\hline P1 & \multirow{6}{*}{ CJ } & P5 & \multirow{6}{*}{$\mathrm{MM}$} & P3 & \multirow{6}{*}{$\mathrm{BN}$} & M19 & $\mathrm{BN}$ & PE23 & CJ \\
\hline P2 & & P7 & & P12 & & M20 & $A B$ & PE24 & $\mathrm{MM}$ \\
\hline P4 & & P8 & & P13 & & M21 & CJ & PE25 & $\mathrm{BN}$ \\
\hline P6 & & P9 & & P14 & & M22 & $\mathrm{BH}$ & PE26 & CJ \\
\hline P17 & & P10 & & P15 & & & & & \\
\hline P18 & & P11 & & P16 & & & & & \\
\hline
\end{tabular}

Tab. 2. Mean values of relative content (\%) obtained for each minor volatile compound separated from plum brandy originating from CJ, MM and BN Counties ( $\mathrm{n}$ - number of analyzed samples)

\begin{tabular}{|c|c|c|c|c|}
\hline \multirow{3}{*}{ No. } & \multirow{3}{*}{ Compound } & \multicolumn{3}{|c|}{ Relative content (\%) } \\
\hline & & $\mathrm{CJ}$ & MM & $\mathrm{BN}$ \\
\hline & & $n=6$ & $\mathrm{n}=6$ & $\mathrm{n}=6$ \\
\hline 1 & Limonene & 4.42 & 3.78 & 0.77 \\
\hline 2 & Butylbenzene & 5.31 & 5.48 & 5.15 \\
\hline 3 & Ethyl benzoate & 5.93 & 5.44 & 4.51 \\
\hline 4 & Decanoic acid & 8.28 & 5.16 & 6.15 \\
\hline 5 & 4-(1-hydroxyethyl) benzaldehyde & 0.33 & 1.14 & 0.36 \\
\hline 6 & Ethyl octanoate & 1.07 & 1.20 & 0.83 \\
\hline 7 & 4-undecene & 0.03 & 0.00 & 0.00 \\
\hline 8 & Methyl decanoate & 0.06 & 0.04 & 0.00 \\
\hline 9 & Ionone & 0.06 & 0.22 & 0.69 \\
\hline 10 & Eugenol & 0.49 & 0.60 & 0.20 \\
\hline 11 & Nonanal diethyl acetal & 0.52 & 0.37 & 0.62 \\
\hline 12 & Ethyl hexanoate & 20.10 & 11.34 & 15.31 \\
\hline 13 & Ethyl cinnamate & 0.81 & 0.94 & 0.24 \\
\hline 14 & Pentyl benzoate & 0.00 & 0.00 & 0.00 \\
\hline 15 & Alpha-farnesene & 1.18 & 1.92 & 3.66 \\
\hline 16 & Ethyl 2,4-decadienoate & 0.76 & 0.00 & 0.40 \\
\hline 17 & Ethyl dodecanoate & 11.23 & 7.75 & 9.29 \\
\hline 18 & Caryophyllene & 0.00 & 0.10 & 1.13 \\
\hline 19 & 5-pentadecen-7-yne & 2.17 & 0.60 & 0.60 \\
\hline 20 & Gamma-elemene & 0.26 & 0.12 & 1.21 \\
\hline 21 & Methyl hexadecanoate & 0.27 & 0.53 & 0.49 \\
\hline 22 & Octyl decanoate & 0.04 & 0.00 & 0.00 \\
\hline 23 & Tetradecanoic acid & 0.00 & 0.08 & 0.37 \\
\hline 24 & 11,13-tetradecadienal & 0.70 & 0.46 & 0.54 \\
\hline 25 & Methyl octa-deca-9,12-dienoate & 0.83 & 0.00 & 1.16 \\
\hline 26 & Ethyl myristate & 3.28 & 3.05 & 4.72 \\
\hline 27 & N-heptadecanoic acid & 0.00 & 0.00 & 0.11 \\
\hline 28 & Phenylethyl benzoate & 0.00 & 0.00 & 0.09 \\
\hline 29 & Ethyl 9-hexadecanoate & 1.60 & 1.98 & 2.00 \\
\hline 30 & Ethyl hexadecanoate & 10.05 & 17.78 & 16.78 \\
\hline 31 & Ethyl octa-deca-9,12-dienoate & 0.00 & 0.11 & 0.00 \\
\hline 32 & Mono-linolein & 15.16 & 20.77 & 16.03 \\
\hline 33 & Methyl 7,10,13-hexadecatrienoate & 4.54 & 7.62 & 5.29 \\
\hline 34 & Ethyl stearate & 0.54 & 1.43 & 1.29 \\
\hline
\end{tabular}

ethyl hexanoate, ethyl dodecanoate, ethyl hexadecanoate and mono-linolein (Tab. 2). Ethyl hexanoate was previously reported in apple brandy (Versini et al., 2009) and in plum brandy (Tešević et al., 2005). Ethyl dodecanoate, being also present in Slovack brandies (Janáčová et al., 2008), has reached the highest amount in CJ plum brandies. Ethyl hexadecanoate was higher in MM plum brandies. Both, ethyl tetradecanoate and ethyl hexadecanoate were present in Slovack brandies (Janáčová $e t$ al., 2008) and in melon distillate (Hernández-Gómez et al., 2005). In plum brandy samples ethyl tetradecanote registered no significant differences between the three regions (Tab. 2). Ethyl octanoate, considered giving in whey spirit a sweetish and fruity aroma (Dragone et al., 2009), it was also found in Slovack and Czech brandies (Janáčová et al., 2008; Satora and Tuszynski, 2010) and in melon distillate (Hernández-Gómez et al., 2005). It was demonstrated that ethyl octanoate comes from fermentation process (Versini et al., 2009). In MM plum brandies registered in our study the highest level, but with no significant differences between the three regions. Also terpenes have a contribution in this discrimination. Limonene, being firstly reported by other authors in plum brandy by GC-MS analysis (Tešević et al., 2005), had similar relative content in CJ and MM plum brandies, and much smaller in $\mathrm{BN}$ samples and registered the highest amount among the terpenes. Alfa-farnesene registered the highest relative content in BN plum brandy samples. Plum brandies from MM County had the highest content in eugenol. This compound gives to plum brandy a cloves aroma, this being the reason of their important contribution to the brandies flavour (Tešević $e t a l ., 2005$ ). It was also found in cornelian cherry (Tešević et al., 2009), plum brandies (Crowell and Guymon, 1973) and in Slovack brandies (Janáčová et al., 2008). Carboxylic acids esters registered similar values between the three regions (Fig.2). Although it has a small amount in our analyzed plum brandies, ethyl cinnamate contributes to the specific plum brandy-like aroma (Tešević et al., 2005, Versini et al., 1995). Ethyl benzoate was determined to have the highest level in the oldest sample of plum brandy (Tešević et al., 2005). In our study this compound does not characterize or distinguish the plum brandies regions (Tab. 2). Long chain fatty acids, with decanoic acid reaching the highest level among them, could also discriminate the three 
Tab. 3. Mean values of relative content (\%) obtained for each of minor volatile compound separated from plum, apple and pear brandies ( $\mathrm{n}-\mathrm{number}$ of analyzed samples)

\begin{tabular}{|c|c|c|c|c|}
\hline \multirow{3}{*}{ No. } & \multirow{3}{*}{ Compound } & \multicolumn{3}{|c|}{ Relative content (\%) } \\
\hline & & Plum brandy & Apple brandy & Pear brandy \\
\hline & & $\mathrm{n}=18$ & $\mathrm{n}=4$ & $\mathrm{n}=4$ \\
\hline 1 & Limonene & 2.99 & 4.54 & 1.82 \\
\hline 2 & Butylbenzene & 5.31 & 4.50 & 11.87 \\
\hline 3 & Ethyl benzoate & 5.30 & 1.35 & 9.80 \\
\hline 4 & Decanoic acid & 6.53 & 6.05 & 11.88 \\
\hline 5 & 4-(1-hydroxyethyl) benzaldehyde & 0.61 & 0.31 & 0.87 \\
\hline 6 & Ethyl octanoate & 1.04 & 0.28 & 1.29 \\
\hline 7 & 4-undecene & 0.03 & 0.00 & 0.00 \\
\hline 8 & Methyl decanoate & 0.05 & 0.00 & 0.00 \\
\hline 9 & Ionone & 0.32 & 0.91 & 0.44 \\
\hline 10 & Eugenol & 0.43 & 0.00 & 0.50 \\
\hline 11 & Nonanal diethyl acetal & 0.50 & 0.00 & 0.00 \\
\hline 12 & Ethyl hexanoate & 15.58 & 14.51 & 19.28 \\
\hline 13 & Ethyl cinnamate & 0.66 & 0.00 & 0.00 \\
\hline 14 & Pentyl benzoate & 0.00 & 0.06 & 0.00 \\
\hline 15 & Alpha-farnesene & 2.25 & 7.16 & 1.28 \\
\hline 16 & Ethyl 2,4-decadienoate & 0.58 & 0.15 & 3.47 \\
\hline 17 & Ethyl dodecanoate & 9.42 & 8.79 & 7.77 \\
\hline 18 & Caryophyllene & 0.41 & 0.84 & 1.84 \\
\hline 19 & 5-pentadecen-7-yne & 1.12 & 0.61 & 0.51 \\
\hline 20 & Gamma-elemene & 0.53 & 0.45 & 1.86 \\
\hline 21 & Methyl hexadecanoate & 0.43 & 0.09 & 0.00 \\
\hline 22 & Octyl decanoate & 0.04 & 0.00 & 0.00 \\
\hline 23 & Tetradecanoic acid & 0.15 & 0.25 & 0.10 \\
\hline 24 & 11,13-tetradecadienal & 0.57 & 0.18 & 0.00 \\
\hline 25 & Methyl octa-deca-9,12-dienoate & 0.99 & 0.88 & 0.45 \\
\hline 26 & Ethyl myristate & 3.68 & 4.31 & 2.95 \\
\hline 27 & N-heptadecanoic acid & 0.04 & 0.15 & 0.00 \\
\hline 28 & Phenylethyl benzoate & 0.09 & 0.23 & 1.73 \\
\hline 29 & Ethyl 9-hexadecanoate & 1.86 & 2.48 & 1.16 \\
\hline 30 & Ethyl hexadecanoate & 14.87 & 13.80 & 6.33 \\
\hline 31 & Ethyl octa-deca-9,12-dienoate & 0.06 & 0.11 & 0.00 \\
\hline 32 & Mono-linolein & 16.67 & 18.63 & 9.23 \\
\hline 33 & Methyl 7,10,13-hexadecatrienoate & 5.82 & 7.69 & 3.42 \\
\hline 34 & Ethyl stearate & 1.09 & 0.70 & 0.14 \\
\hline
\end{tabular}

regions, MM plum brandies having the smallest content. Decanoic acid was also identified in Slovack brandies by GC-MS using LLE and SPME (Janáčová $e t$ al., 2008). Tetradecanoic acid appeared in Slovack brandies as well (Janáčová et al., 2008) and in cornelian cherry alcoholic beverage (Tešević et al.,2009).

\section{Comparative data of GC-MS analysis depending on the brandies type}

The obtained data were similar with the results reported by other references on fruit brandies. The ethyl esters of fatty acids detected by GC-MS shown a strong dependence on the type of fruit brandy and their origin region. Also comparing the three assortments, the most abundant compounds were ethyl esters of fatty acids having the highest amount for ethyl hexanoate, ethyl dodecanoate, ethyl hexadecanoate and mono-linolein (Tab. 3). Among the fatty acids esters, ethyl hexanoate has reached the highest amount, with significantly different value in pear brandy. Both, ethyl dodecanoate and ethyl hexadecanoate shown the most important content in plum brandy samples and mono-linelein in apple brandy (Tab. 3). In another study, plum brandy was the richest in ethyl hexadecanoate (Winterová et al., 2008). By analyzing different fruit spirits, the richest amount of ethyl tetradecanote was found in apple brandy (Winterová et al., 2008), fact also confirmed by our study, but with similar amount as plum brandy (Tab. 3). Ethyl octa-deca-9,12-dienoate, methyl octadecanoate and ethyl stearate were also identified in cornelian cherry alcoholic beverage and in melon distillate
(Hernández-Gómez et al., 2005; Tešević et al., 2009). The last two compounds registered similar concentrations (Tab. 3). Ethyl 2, 4-decadienoate is a specific compound for pear brandies (Diban et al., 2009; Garcia-Llobodanin et al., 2008). This fact is also confirmed by our values, because it strongly characterizes the pear brandies (Tab. 3). Methyl hexadecanoate was found in apple, pear, plum, sour cherry and apricot brandies and registered the highest amount in the last one (Winterová et al., 2008). The fatty acid esters contribute to the flavour of brandies with a pleasant fruity and flowery smell in Opuntia ficus brandies. Ethyl esters could increase their amounts and also the quality of the spirits, during the aging process of brandies (Gerogiannaki-Christopoulou et al., 2008). Carboxylic acids esters with ethyl benzoate having the highest amount discriminate very well the three types of brandies (Tab. 3). Considering the terpenes, alfa-farnesene had the highest content and it is notably dominant in apple brandy comparing to other two assortments (Tab. 3). This compound gives an apple-like quality scent and a fresh floral terpenyl topnote (Versini et al., 2009). Limonene had also the highest amount in apple brandy (Tab. 3). Analyzing by GC-O coupled with GC-MS, it was demonstrated limonene giving a citrus odour in mandarins (Tietel et al., 2011). Limonene contributed to the specific aroma of cornelian cherry alcoholic beverage along with caryophyllene (Tešević et al., 2009). Here, caryophyllene registered the highest level in pear brandies. In a study conducted on apple brandies, eugenol had different concentration values giving a spicy 
535

tone to the brandy, depending on the year of production rather than the variety (Versini et al., 2009). Among pear, apple and plum brandies, the last had the highest content in eugenol (Winterová et al., 2008). In the present study, eugenol registered similar amount in plum and pear brandies (Tab. 3). Long-chain fatty acids have a small influence to the flavor of brandies. Other studies reported octanoic, nonanoic, decanoic, dodecanoic and hexadecanoic acids as being the most abundant acids (Tešević et al., 2009). Decanoic acid was one of the main volatile compounds identified in melon distillate (Hernández-Gómez et al., 2005). We also report this compound as being the most abundant fatty acid (Tab. 3).

The results obtained by the GC-MS analysis presented in both Tab. 2 and Tab. 3 were further interpreted using PCA. Sub-collective comprising of plum brandies was analyzed (Fig. 3). The first two PCs describe $74 \%$ of the total variability of the data. The variance in PC-1 discriminates the plum brandies samples originated from $\mathrm{CJ}$ (samples P1, P2, P4, P6, P18) between those from MM (samples P5, P7, P8, P9, P10, P11) and BN (samples P3, P12, P13, P14) Counties, by their content in ethyl hexadecanoate. From Tab. 2 and PCA discrimination by loadings (data not shown) it can be seen that ethyl hexadecanoate is the main influence factor for this discrimination. Ethyl hexadecanoate also delimitates samples from the same region (BN County) P15 and P16 from P3, P12, P13 and P14. The variance in PC-2, which describes $27 \%$ of the data variation, is attributed to the content in limonene. Among plum brandy samples, P17 it has the highest relative content in limonene (Fig. 3).

By taking into consideration the mean values obtained for all individual samples, the first two principal components (PC-1 and PC-2) are plotted in Fig. 4. They explain $66 \%$ of the variance, three samples of apple brandy (M19, M21 and M22) being differentiated by the content in ethyl hexadecanoate. They are also characterized by a reduced content in ethyl hexanoate. This fact is also confirmed by the PCA loadings representation (data not shown). Samples of pear brandy and, especially sample PE26, are being discriminated by ethyl benzoate (Tab. 3, Fig. 4).

The principal components (PC-1 and PC-2) explain 87\% of the variance when representing the mean values of different types of brandy and the plum brandy from the three regions (Fig. 5). It was a visible delimitation of the three types of fruit brandies, with an exception, in the case of CJ plum brandy, which registered discriminated differences with $\mathrm{MM}$ and BN plum brandies (the principal discriminated factor being ethyl hexadecanoate) (Tab. 2). PCA demonstrated that CJ plum brandy and apple brandy samples have quite similar composition (Fig. 5). The important role of this similarity it is attributed to limonene, suggesting that CJ plum brandies are possibly adulterated with apple brandy. PC-1 mainly differentiates pear brandy to plum and apple brandies, having a high contribution to this differentiation (75\%) (Fig. 5). Delimitation of pear brandies (Fig. 5), it is explained by the content in ethyl 2, 4-decadienoate, which is a specific compound for pear brandy. Pear brandies differ from the other two brandies by their higher amount in ethyl hexanoate, ethyl benzoate and decanoic acid (Tab. 3).

We can conclude that Principal Component Analysis was capable to create good associations regarding these three types of brandies. The representative compounds (in high

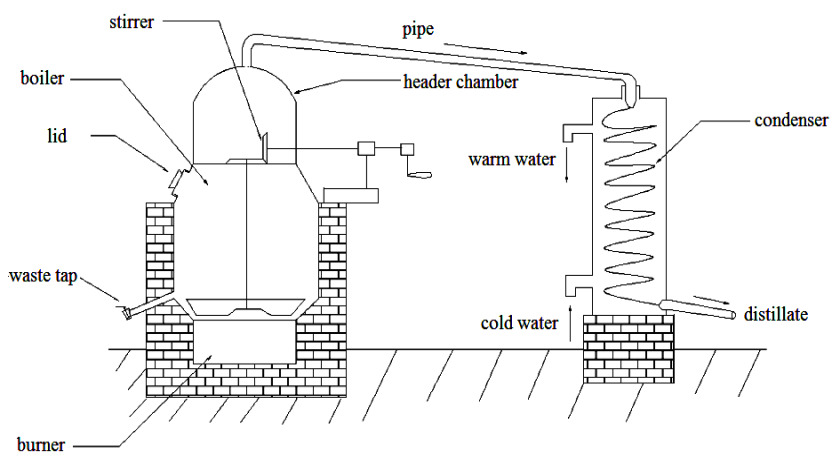

Fig. 1. The copper alembic with open fire (adapted after Pomohaci et al., 2009)

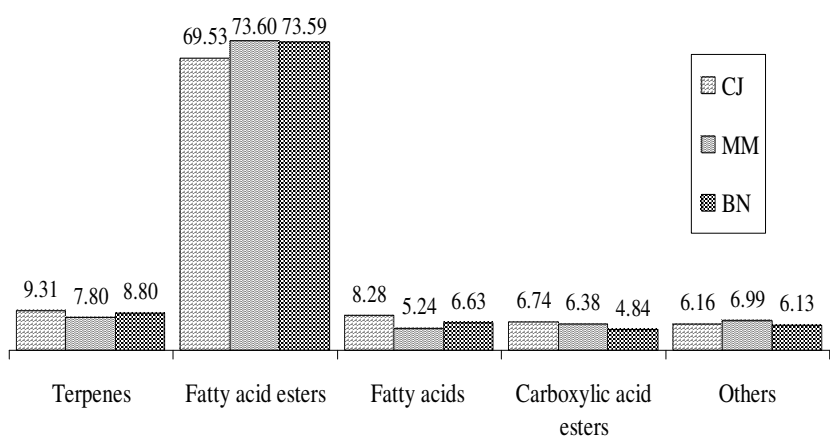

Fig. 2. Percentage values of each class of compound found in plum brandies from the three counties (CJ, MM and BN)

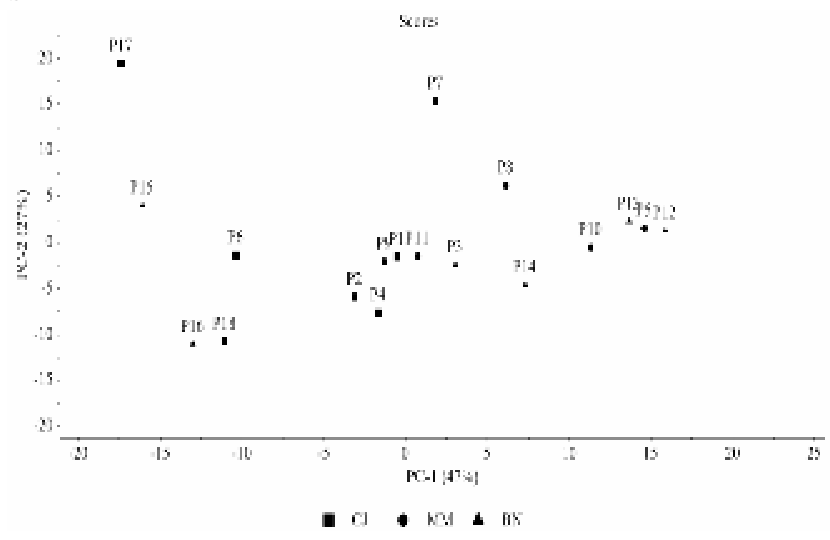

Fig. 3. PCA discrimination for individual values (scores) of plum brandies volatile compounds originated from CJ, BN and MM counties analyzed by GC-MS

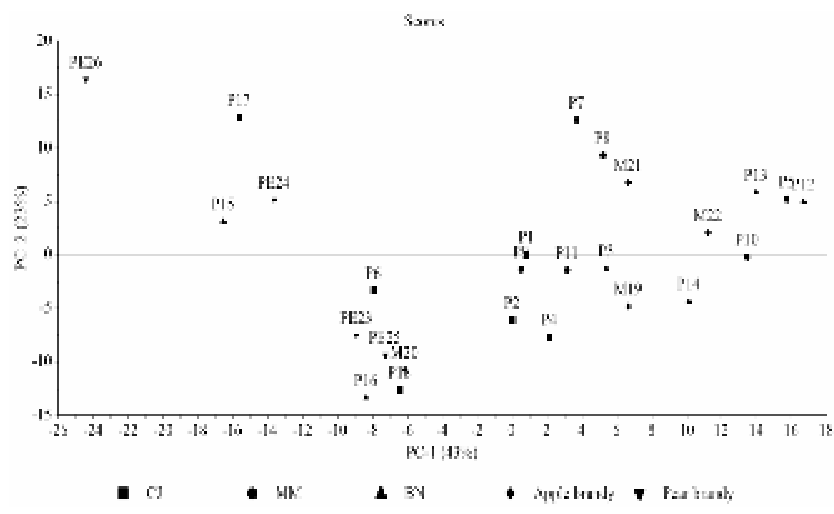

Fig. 4. PCA discrimination considering the individual volatiles values of plum, apple and pear brandies (scores) analyzed by GC-MS 


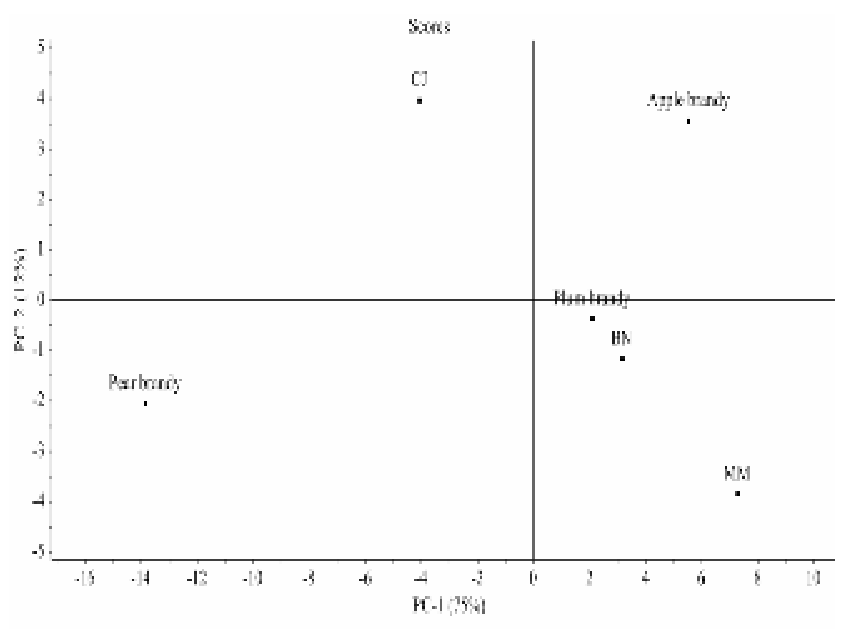

Fig. 5. PCA applied to discriminate based the main volatile compounds (analyzed by GC-MS) from plum, apple and pear brandies dependent on their provenience (CJ, BN, MM counties of Romania)

concentrations in these types of fruit brandies) such as ethyl esters of hexanoic, benzoic, hexadecanoic and dodecanoic acids make possible these associations.

\section{Conclusions}

The results obtained by GC-MS analysis of 26 samples of traditional fruit (plum, apple and pear) brandies from Transylvania, have shown that the type of brandies and the provenience region of plum brandies are reflected by different minor volatiles patterns, which influence the flavour and the quality of these fruit brandies. There were identified volatiles from different classes: fatty acid ethyl esters, terpenes, carboxylic acid esters, free fatty acids, hydrocarbons, aldehydes and acetals. Ethyl esters of fatty acids played an important role for samples discrimination. Taking into consideration the plum brandy (tuica) samples, we could distinguish important differences among samples from different counties (CJ comparing with $\mathrm{MM}$ and $\mathrm{BN}$ ). Ethyl hexadecanoate was the main factor for this discrimination. The comparison of the three types of fruit brandies suggested significant differences, by the content in ethyl esters of hexanoic, benzoic, dodecanoic and hexadecanoic acids. Interestingly, the fingerprint of from CJ plum brandies was similar to apple brandy in limonene content, suggesting a possible adulteration with apple brandy. The pear brandy was identified specifically by its specific content in ethyl benzoate, ethyl hexanoate, decanoic acid and ethyl 2, 4 - decadienoate, the last one being considered as a specific biomarker for pear brandy. By PCA, it was discriminated the type and the provenience of the fruit brandies and the important common or specific biomarkers.

\section{Acknowledgements}

This work was supported by the National Institute of Research and Development for Isotopic and Molecular Technology (INCDTIM) Cluj-Napoca, Romania.

\section{References}

Anli ER, Vural N, Gucer Y (2007). Determination of the principal volatile compounds of Turkish Raki. J Inst Brew 113(3):302-309.

Beceanu D, Niculaua M (2009). A comparative study of an assortment of plum distilled drinks, made in Romania. Cercetari Agronomice in Moldova 42(3):49-61.

Butkhup L, Jeenphakdee M, Jorjong S, Samappito S, Samappito W, Chowtivannakul S (2011). HS-SPME-GC-MS analysis of volatile aromatic compounds in alcohol related beverages made with mulberry fruits. Food Sci Biotechnol 20(4):1021-1032.

Cabaroglu T, Yilmaztekin M (2011). Methanol and major volatile compounds of Turkish raki and effect of brandy source. J Inst Brew 117(1):98-105.

Caldeira I, Pereira R, Clímaco MC, Belchior AP, Bruno de Sousa R (2004). Improved method for extraction of aroma compounds in aged brandies and aqueous alcoholic wood extracts using ultrasound. Analytica Chimica Acta 513(1):125-134.

Cardoso DR, Andrade-Sobrinho LG, Leite-Neto AF, Reche RV, Isique WD, Ferreira MMC, Lima-Neto BS, Franco DW (2004). Comparison between cachaca and rum using pattern recognition methods. J Agric Food Chem 52(11):3429-3433.

Christopoulou-Gerogiannaki M, Gerogiannaki I, Anagnostartas E, Stavrakas DE, Polissiou M (2007). Identification of volatile compounds in Hellenic alcoholic beverages from native white grape varieties (Vitis vinifera L.). J Food Technol 5(3):233-241.

Cortés S, Rodríguez R, Salgado JM, Domínguez JM (2011). Comparative study between Italian and Spanish grape marc spirits in terms of major volatile compounds. Food Control 22(5):673680.

Crowell EA, Guymon JF (1973). Aroma constituents of plum brandy. Am J Enol Vitic 24(4):159-165.

De León-Rodríguez A, Escalante-Minakata P, Jiménez-García MI, Ordoñez-Acevedo LG, Flores Flores JL, Barba de la Rosa AP (2008). Characterization of volatile compounds from Ethnic Agave alcoholic beverages by gas chromatography-mass spectrometry. Food Technol Biotechnol 46(4):448-455.

Delgado R, Durán E, Castro R, Natera R, Barroso CG (2010). Development of a stir bar sorptive extraction method coupled to gas chromatography-mass spectrometry for the analysis of volatile compounds in Sherry brandy. Anal Chim Acta 672(1-2):130136.

Diban N, Voinea OC, Urtiaga A, Ortiz I (2009). Vacuum membrane distillation of the main pear aroma compound: experimental study and mass transfer modelling. J Membrane Sci 326(1):64-75.

Dragone G, Mussatto SI, Oliveira JM, Teixeira JA (2009). Characterisation of volatile compounds in an alcoholic beverage produced by whey fermentation. Food Chem 112(4):929-935.

Garcia-Llobodanin L, Ferrando M, Guell C, Lopez F (2008). Pear distillates: influence of the raw material used on final quality. Eur Food Res Technol 228(1):75-82.

Gerogiannaki-Christopoulou M, Tzoutzoukou C, Masouras T (2008). Evaluation of macro- and micro- volatiles in Hellenic local 
alcoholic beverage from Opuntia Ficus (Fragosyko). Agricultural Journal 3(5):429-438.

Gracia I, García MT, Rodríguez JF, De Lucas A (2009). Application of supercritical fluid extraction for the recovery of aroma compounds to be used in fast aged rum production. Food Sci Technol Res 15(4):353-360.

Hernández-Gómez LF, Úbeda-Iranzo J, Briones A (2008). Characterisation of wines and distilled spirits from melon (Cucumis melo L.). Int J Food Sci Tech 43:644-650.

Hernández-Gómez LF, Úbeda-Iranzo J, García-Romero E, BrionesPérez A (2005). Comparative production of different melon brandies: chemical and sensory analyses. Food Chem 90(12):115-125.

Janáčová A, Sádecká J, Kohajdová Z, Špánik I (2008). The identification of Aroma-Active Compounds in Slovak Brandies Using GC-Sniffing, GC-MS and Sensory Evaluation. Chromatographia 67:113-121.

Laaks J, Jochmann MA, Schilling B, Molt K, Schmidt TC (2014). InTube Extraction-GC-MS as a High-Capacity Enrichment Technique for the Analysis of Alcoholic Beverages. J Agric Food Chem 62 (14):3081-3091.

López-Vázquez C, Bollaín MH, Berstsch K, Orriols I (2010). Fast determination of principal volatile compounds in distilled spirits. Food Control 21(11):1436-1441.

Lukić I, Miličević B, Banović M, Tomas S, Radeka S, Peršurić Đ (2011). Secondary aroma compounds in fresh grape marc brandies as a result of variety and corresponding production technology. Food Technol Biotechnol 49(2):214-227.

Moldovan Z (2006). Occurrences of pharmaceutical and personal care products as micropollutants in rivers from Romania. Chemosphere 64(11):1808-1817.

Order No. 368/2008 for approving the norms regarding the definition, description, presentation and labelling of traditional Romanian drinks

Plutowska B, Biernacka P, Wardencki W (2010). Identification of volatile compounds in raw spirits of different organoleptic quality. J Inst Brew 116(4):433-439.

Pomohaci N, Cioltean I, Popa A, Modoran D, Bunea A, Visan L, Chioran I (2009). Producerea băuturilor alcoolice tradiţionale în T,ara Pălincii. Editura Ceres, București.

Regulation 110/2008 of the European Parliament and of the Council. 15 January 2008 on the definition, description, presentation, labelling and the protection of geographical indications of spirit drinks and repealing. Council Regulation (EEC) No 1576/89. Official Journal of the European Union 51(39):16-54.

Rodrigues F, Caldeira M, Câmara JS (2008). Development of a dynamic headspace solid-phase microextraction procedure coupled to GC-qMSD for evaluation the chemical profile in alcoholic beverages. Anal Chim Acta 609(1):82-104.

Sarvarova NN, Cherkashina YuA, Evgen'ev MI (2011). Application of chromatographic methods to the determination of cognac quality indicators. J Anal Chem 66(12):1190-1195.
Satora P, Tuszynski T (2005). Biodiversity of yeasts during plum Wegierka Zwykla spontaneous fermentation. Food Technol Biotechnol 43(3):277-282.

Satora P, Tuszynski T (2008). Chemical characteristics of Śliwowica Łącka and other plum brandies. J Sci Food Agr 88(1):167-174.

Satora P, Tuszynski T (2010). Influence of indigenous yeasts on the fermentation and volatile profile of plum brandies. Food Microbiol 27(3):418-424.

Sohrabvandi S, Mortazavian AM, Rezaei K (2011). Advanced analytical methods for the analysis of chemical and microbiological properties of beer. J Food Drug Anal 19(2):202222.

Soufleros EH, Mygdalia SA, Natskoulis P (2005). Production process and characterization of the traditional Greek fruit brandy "Kumar" by aromatic and mineral composition. J Food Compos Anal 18(7):699-716.

Tešević V, Nikićević N, Jovanovic A, Djokovic D, Vujisic L, Vučković I, Bonic M (2005). Volatile components from old plum brandies. Food Technol Biotechnol 43(4):367-372.

Tešević V, Nikićević N, Milosavljević S, Bajić D, Vajs V, Vučković I, Vujisić L, Đorđević I, Stanković M, Veličković M (2009). Characterization of volatile compounds of "Drenja", an alcoholic beverage obtained from the fruits of cornelian cherry. J Serb Chem Soc 74(2):117-128.

Tietel Z, Porat R, Weiss K, Ulrich D (2011). Identification of aromaactive compounds in fresh and stored 'Mor' mandarins. Int J Food Sci Tech 46(11):2225-2231.

Vera-Guzmán AM, Guzmán-Gerónimo RI, López MG (2010). Major and minor compounds in a Mexican spirit, young mezcal coming from two Agave species. Czech J Food Sci 28(2):127-132.

Versini G, Franco MA, Moser S, Barchetti P, Manca G (2009). Characterisation of apple brandies from native varieties of Sardinia Island and comparison with other Italian products. Food Chem 113(4):1176-1184.

Versini G, Franco MA, Moser S, Manca G (2012). Characterization of pear distillates from wild and cultivated varieties in Sardinia. Int J Food Sci Tech 47(12):2519-2531.

Versini G, Seeber R, Dalla Serra A, Sferlazzo G, De Carvalho B, Reniero F (1995). Aroma compounds of arbutus distillates. Dev Food Sci 37:1779-1790.

Winterová R, Mikulíková R, Mazáč J, Havelec P (2008). Assessment of the authenticity of fruit spirits by gas chromatography and stable isotope ratio analyses. Czech J Food Sci 26(5):368-375. 